\title{
A-signifying Semiotics
}

\author{
Gary Genosko \\ Department of Sociology \\ Lakehead University \\ gary.genosko@lakeheadu.ca
}

\begin{abstract}
This paper offers an interpretation of the theory of a-signifying semiotics developed by French intellectual-activist Félix Guattari in the 1970s. The argument is that these types of part-signs are perfectly adapted to the quasiautomated networks of contemporary infocapitalism, and their characteristics are studied with regard to the magnetic stripe on a plastic bank or credit card. Although these part-signs are akin to signals since they do not have a semantic dimension, they do have a political materiality in the technologies, that is, the information strands of the machinic phylum, in which they are found. This technomaterialist semiotics of infocapital places Guattari at the forefront of innovative semiotic theory.
\end{abstract}

Keywords: A-signifying semiotics, part-signs, Félix Guattari, networks, magnetic stripes, infocapital

\section{Introduction}

Signals are the poor semiotician's stock-in-trade. They are not considered signs proper since, as Umberto Eco (1976:20) explains, they 'can be computed quantitatively irrespective of their possible meaning'. Signals thus on this view occupy 'the lower threshold of semiotics' (1976:33). Signaletic stimuli do not appear to require higher-level semiotic functions engaging cultural contents or the kind of effects that typically emerge in and from the movement between signifiers.

My task is to rethink and regain the lowly status of signals through the explication and deployment of the category of a-signifying semiotics developed by Félix Guattari. To this end two initial reorientations are required. First, the prejudicial hierarchisation of signals as low ranking phenomenon, under the semantic horizon of cultural conventions of interpretation, will be suspended. Second, the quantitative or machinic qualities of signals will form a positive part of their reassessment, rather than serve to confirm their lowly status against a higher order domain in relation to which they, by definition, can never measure up. Signals, in short, have a good deal to teach about a-signifying semiotics; indeed, the category of the latter considerably deepens and revivifies the former sort of 'lowly' sign type by unleashing, as a heuristic virtue, the characteristics of this status.

Guattari attempted to develop the first semiotics adapted to the global information economies of the network society, even though his untimely passing in 1992 did not permit him to experience the extraordinary accelerations of the 1990s towards and beyond the millennium of the burgeoning infotechnocultural era of digital capitalism; still, he was already attentive to the stirrings of the fusion of capitalism and informatics in his studies dating from the 1980s of the global economy of Integrated Worldwide Capitalism. It was on the information technology strand of the 'machinic phylum' that IWC exercised its formidable integrative capacities inaugurating 'the age of planetary computerization'; this has been developed at length by Manuel DeLanda (1991:20; Guattari 1989:42-3) in terms of the military machine's extractions, its taking hostage of operations and applications, from the information processing strand. Guattari struggled against IWC's appropriations 
from the same technological strand for the sake of the production of certain kinds of subjects compatible with most of its values, stratifications, and disorienting visions of progress. For example, he thought that miniaturization was a way for capital to equip individuals with devices that would manage their perceptions by plugging them into strands of the machinic phylum concerned with consumer electronics (iTunes, iPods, iSubjects), making them crazy for self-medicated highs of the kind that come from the aptly rechristened CrackBerry (Guattari 1995a:103).

Guattari sought to frame these issues in semiotic terms and to theorize a species of part-signs that expose salient features of informatized capital in whose networks they directly intervene by exploiting the potentiality materially present there. Guattari wrote of 'signaletic matter' in a manner similar to Deleuze (1989:29) in his cinema books, especially The Time-Image: the seething, dynamic stew of largely unformed but not completely amorphous matter out of which part-objects (including part-signs), as well as more fully and creatively expressive and formed semiotic substances, emerge. Obviously, the kinds of signs Deleuze had in mind were images. Basically, signaletic matter is defined as a-signifying. Both Guattari and Deleuze reverse the priority of form over matter inherited from De Saussure and Hjelmslev, and in this way attempt to describe a process of teasing out what are already there in part and in varying degrees. With a-signifying semiotics, however, this work of teasing out never gets to linguistic formation; it is reticent, hesitant, working only with the parts and their intensities, without imposing on them further form: signification never culminates.

\section{A-signifying Molecular Revolutions}

In a cluster of books published originally in 1977, the two editions of La révolution moléculaire (1977a and b) and L'inconscient machinique (1979), Guattari elaborated a typology of semiotic systems framed in a Peirce-Hjelmslev hybrid conceptual vocabulary. Reading across these three books I want to flesh-out a-signifying semiotics in relation to an infotech strand on the machinic phylum inspired by one of Guattari's favourite examples of the kind of semiosis put into play by a-signifying signs: credit and/or bank cards. Guattari's innovation was to develop a-signifying signs in a typology of sign types but with respect to the problem of the relationship between material and semiotic dimensions in the age of planetary computerization and globalization. Is there a semiotics adequate to the global information culture? Yes, just as there is an analysis of power of the same in the myriad of attempts to describe its features - for example, its non-linearity (Lash 2002:18ff). A-signifying signs, to the extent that they are at work there, bear some of its features, including superlinearity, which they operationalize. The very texture of the informatic strand of the machinic phylum upon which capital relies is populated better, perfused - by a-signifying part-signs.

One of the main obstacles to thinking a-signification is that the promise of the prefix may not be kept by the suffix, which clings stubbornly to signification despite an opening to elude it. So, a-signifying understood as non-signifying semiotics seems at best an oxymoron and at worst simply a species of signals. A-signifying signaletic matter may be non-signifying in the sense that signals directly transmit information without necessarily providing semantic content, on a slightly more progressive view than that of Eco (Ruse 1998:576). This corresponds minimally to Guattari's sense of a-signifying signs, usually referring to non-linguistic information transfers. But more to the point is that no specific construal of that 
which emanates from the system is required in support of the action thereby triggered. The concept's marginality does not imply the absence of the action initiated by the triggering signal. Importantly, the absence of a semantic dimension is less pertinent than the non-representational and non-mental dimension. Guattari is less concerned about limiting the semantic than underlining the strictness and precision of a-signification. In fact, a-signification operates by means of part-signs, that is, particle-or point signs, as Guattari called them, and not through the fully formed signs of any tradition. But the restrictiveness of a-signification, the partial/particle/ point-ness of such signs, and their non-representational character, entails for Guattari a micropolitical analysis of this kind of semiotics. So, in this respect a-signifying semiotics differs from signaling since the non-necessity of semantic content is not negatively construed as denying something to someone (i.e., to signal using animals as opposed to the ability of immune cells to multiply protectively against an invading microbe) and does not entail some variant of behaviorism.

Let's begin with an apparently simple idea. A-signifying semiotics are defined relationally by Guattari against signifying semiologies. Guattari maintains the distinction between semiotics - Peircean-Hjelmslevian hybrid - and semiology - Saussurean, or dyadic and linguistic. There are of course many other ways to reinforce the distinction, for example with regard to the inclusion or exclusion of the referent, but the salient point is that a semiotics that is not dependent upon linguistics loosens, for Guattari, the hold that structuralism enjoys, in collusion with psychoanalysis, over the construction of the unconscious, that is, all the features of a formal description of its components - 'universals', 'laws', 'registers', transcendent figures like 'lack', etc. Guattari's great innovation was to conceive of the unconscious as a machine that was neither structured like a language nor conceptualized as an interior struggle within individuals indexed on static mythic figures or even mathemes: 'it was a grave error on the part of the structuralist school to try to put everything connected with the psyche under the control of the linguistic signifier!' (Guattari 1995b:5) Correcting this grave error, and thus escaping from 'linguistic axiomatics', involves bringing to the fore the machinic processes of a-signifying semiotics irreducible to semiolinguistic determinations. Guattari (1979:13) exhorts his readers to sortir de la langue. Machines constitute according to Guattari a kind of 'changing matter' that dynamically assemble as well as undo components drawn from diverse domains and extract from these their singularity traits (hybrid identities), not all of which will be constituted but remain virtual (pure potential).

Signifying semiologies concern well-formed substances situated on the stratified planes of expression and content with the proviso that all such substances are linguistified; symbolic semiologies are a species of signifying semiologies and concern substances of expression that are neither completely translatable into linguistic terms nor may they be overcoded by any one substance of expression among them. This rule of non-translatability keeps at bay linguistic imperialism: 'the semiological linearity of the structural signifier which imposes itself despotically over all other modes of semiotisation' (Guattari 1995b:49).

Signifying semiologies are, as in Saussure, structured by the axes of syntagm and paradigm; the former is a series of terms in praesentia (co-present) supported by linearity whereas paradigmatic relations are constellative, indeterminate, and in absentia (lacking co-presence); a-signifying semiotics, it has been suggested, elude these axes and 'add a third, diagrammatic axis' (Bosteels 1995:353). But what is the point of adding another axis? Simply put, it announces an attempt to break 
away from the horizontal syntagm and the vertical paradigm, that is, from speech and language; taken together these are the tools of a 'trans-linguistic semiology' (Barthes 1967:11 and 86). This is a conservative maneuver, at best. Because even Barthes, one of Guattari's semiological nemeses, thought that 'creative transgressions' - 'structural scandals' (Barthes 1967:89) can occur at the frontier of syntagm and paradigm, even if these are still glottic - puns, spoonerisms, rhymes, and the like. The Peirce-inspired diagrammatism elaborated by Guattari will be discussed later. The question for Guattari is not one of transgression but of the limits and controls on any semiotic deviation or deterritorialization.

So, is it enough to 'disturb' (Semetsky 2004:243) by addition inherited binarisms like syntagm and paradigm? After all, disturbances do not persist with the same strength of the new over time and perhaps nestle comfortably into routines. It would be easy to trap a third axis in the production of a certain kind of subjectivity if it was always linked to a specific expression substance like a despotic signifier. This despotism may be deposed if it is linguistic, but its relation to power, even the power of the psychoanalyst, is not vanquished.

Guattari (1977a:230-1) is never done with signifying semiologies. 'Signification is always the encounter between the formalization [of both expression and content] by a given social field of value systems, translation systems, rules of conduct, and a machine of expression which by itself has no meaning, that is, which is a-signifying and automates the behaviors, interpretations and the responses hoped for by the system'. Signification occurs in the conjunction of semiotic and semiological systems, marked by the stratifications of power actualized in informatic, economic and social and political terms. For instance, Guattari (1977b:243) reads the sign's arbitrariness as a 'basic' social and political demand: 'accept the systems of dominant encodings in which everything is done for you or you will end up with a repressive system'. A-signifying signs 'automate' dominant significations by 'organizing a system of redundancy" on the levels of expression and content: automation entails normalization, invariance and consensus. Guattari adds the further qualification of stabilization - what is arrested is wandering in textual space amid the mandalas of signification. There isn't any room for interpretation in the strings of numbers and characters on a typical magstripe: framed by start and stop sentinels, field separators between system/bank/account/and redundancy check, all of which are recognized automatically, and have limited numbers of characters. In themselves a-signifying signs have no meaning but they operationalize local powers - for Guattari - here we see how he jumps from machinic-trigger to political level and back again - they are akin to the 'role of the State in relation to different factions of the bourgeoisie that consists in setting in order and hierarchizing the claims of various local factions' (Guattari 1977b:243). Sectoral interests and their lobby groups and regional political organizations with territorialized power bases are among such local factions whose claims are parsed and prioritized by a central power in terms of political agenda-setting, favour-trading, and policy formation. These kind of political decisions are encoded in the magstripe, as we will see shortly.

Signifying semiologies and their linear 'syntagms of power' combine with superlinear a-signifying automations. Guattari tended to compile lists of diverse encodings to explain the semiotic mixity of assemblages. But the conception is clear as far as the relations between signifying and a-signifying is concerned: the latter uses, puts them into play in some manner, as it were, the former only as a 'tool' 
and without themselves functioning either semiologically or symbolically; in this way a-signifying semiotics are not subjected to semiological well-formedness, but to which they still have recourse in communicating in the way that 'dominant significations 'hope for' - which is to say if one wants to be taken seriously by semioticians, at the very least. But, Guattari (1977b:281) boldly stated, a-signifying semiotics 'can do without this kind of crutch'. He also claims that signifying semiologies are capable of 'deriving their efficacity from the fact that they rely upon a certain a-signifying machine' (Guattari 1977a:236). That is, they may find the deterritorializing tendencies of a-signifying semiotics helpful in blurring the territories of the body or certain institutional spaces. But in the very crossing between systems and generation of significations new territories are breached and powers engaged perhaps leading to the imposition of a more rigid definition, or with claims of incoherence.

\section{Plastic Cards, Magstripes and Technomateriality}

A-signification is essentially machinic. Guattari did not reduce his machines to technical devices; yet, his repeated description of the how a-signifying semiotics trigger processes within informatic networks highlights the interactions initiated with a plastic card bearing a magnetic stripe in activating access to a bank or credit account, engaging an elaborate authorization process, makes it clear that we are dealing with a complex info-technological network. Here Guattari's 'part [sometimes particle]-signs' - the names he bestowed upon the signs of a-signifying semiotics - 'give out start and stop orders' (Guattari 1995b:49). It is easy to think of part-signs as actual iron oxide particles on the tracks of the magnetic stripes of credit cards that are decoded - their polarities are immediately converted into binary digits - when 'swiped' through a reader with the appropriate software. As everyone knows, there is normally more to the operation than the gestural act. Of course, the use of 'particles' by Guattari tells us that the signs of a-signifying semiotics are just as much virtual - 'elementary' entities that are generated by machinic interactions like acceleration and mathematical prediction and whose existence is verifiable theoretically (Watson 2002:35).

Anyone who has received a error message in the process of inputting a PIN/ password, which is usually the second step in the process, in the course of a debit transaction or log-in operation understands the overt syntagmatic sensitivity of such part-signs (and in most cases the syntactical features - how many digits, upper and lower case sensitivity - of a password or PIN). Indeed, anyone who has had their card eaten by a machine knows the vicissitudes of a-signification - perhaps this is just a jammed trigger but it may be a security countermeasure triggered by the card's use in such a place for such a purpose against an established or even extrapolated pattern; moreover, when a card is as one says 'all swiped out' by intense usage, after a shopping spree, the kind of interaction between the oxide particles on its magnetic stripe and the reader head that converts the encoding into binary digits goes awry because the magstripe is scratched or erased or demagnetized, thus introducing imbalance into the signal/noise ratio.

A-signifying part-signs do not slide; conversely, if they experience any sort of drift, they cease working. Guattari (1977a:235) provides a helpful description of the precise character of such signs: 'It is as if [they] ideally sought to shed their own inertia and renounce completely the polysemy which can proliferate in symbolic and signifying systems: the sign is refined, there is no longer 36 possible interpre- 
tations but a denotation and an extremely strict and precise syntax'. The ' 36 ' is of course a reference to Peirce's strategy of generating categories of signs by means of combining triadic divisions; today this is how we order overpriced coffee! The precision of the syntax is a more difficult issue to grasp. Whereas Deleuze considered a-signifying signaletic matter to be a-syntaxic, Guattari retains syntactic combinatorics of minimal units but without a necessary reference to deep/underlying or high/transcendent semantics; he can maintain this because the primary context is not language. Further, point-signs work regardless of whether they signify something for someone or not. As Guattari specifies, they do not 'secrete significations' - whether these are 'thoughts', 'psychical' entities, or 'mental representations. Take a minimal definition of the sign - something that stands to somebody for something else - and incapacitate representation, Guattari's position becomes a bit clearer: 'Signs 'work' things prior to representation. Signs and things combine with one another independently of the subjective 'hold' that the agents of individuated enunciation claim to have over them' (Guattari 1977b:282). However, having incapacitated a disempowering representation and brought signs and things, that is, the material and the semiotic closer together, Guattari adds that this is the 'force of machinic assemblage' (as opposed to a disempowered semiology).

Whether they are randomly generated or carefully selected on the basis of paradigmatic clusters of birthdates, children's ages, former addresses, initials, nicknames, etc, PINS/passwords can, like the magstripe-reader encoding-decoding relation, do without mental representations; these latter may of course exist but they are 'never essential' and no longer center signification. With a-signifying semiotics there is no need, Guattari (1979:224) insisted, on passing through the summit of a typical pyramid of meaning, that is, through an already constituted referent, soul, substance, individuated subject's mental universe, etc. It is just as if, Guattari (2006:387) conjectured, physics 'renounce[d] any attempt to signify anything other than its own machinic articulations' in generating particles it multiplies by means of signs (whose productivity is their only relevant property). Certainly, Guattari (1977a:235) believed, one can create scientific representations of subatomic particles, but 'these cannot be taken into account by scientific semiotisation'. The study of such representations is of interest to many technocultural theorists, philosophers and sociologists of science, but Guattari underlines the limits of their pertinence and translatability.

The fallout for semiology is that new relations are established between form and matter by part-signs in as much as they skirt substance in some manner; there is a tendency in the information age for a-signifying semiotics to maximize its machinic force - to rapidly evolve, speed up, acquire greater mobility, miniaturize, and proliferate. In a-signifying semiotics part-signs work 'flush' (travaillent à même) with the real, more precisely, with material fluxes. Guattari does not, however, uncritically valorize flushness as directness. At the same level as and in parallel is perhaps better. Directness has important qualifications.

\section{Diagrams and Part-Signs}

Regaining, then, part-signs, Guattari explains that these show how sign-referent relations may be reconceived. Modeling his conception on subatomic particles like quarks, Guattari does not seek positive evidence of the existence of part-signs in referential anchors like space-time coordination and logical consistency, but notes how certain perceptions actualize them in specific ways; as Brian Massu- 
mi (1992:53) put it, 'scientific perception actualizes a virtual particle'. The problem of existence is imposed on them retroactively and: 'A new type of relation is established between the sign and referent, no longer a direct relation, but a relation engaging [mettant en jeu] a theoretico-experimental assemblage in its entirety' (Guattari 1977b:244). Two points are worth making as we, taking Guattari's advice, work out the implication of the physics lesson in other domains. The first is that part-signs engage machinic material processes beyond the problem of referentiality whose quandaries have always haunted semioticians. They are able to do so because such signs are creatures of the matière signalétique - signalizing matter - they constitute through machinic electromagnetic interactions, as in my magstripe example. Secondly, Guattari suggests that entire experimental assemblages are engaged, that is, IT networks of hardware and software, international standards of practice and production, requests for authentication from remote databases, supporting the signalizations of part-signs, again in a credit request situation. In this immense information infrastructure, delimited for the time being by the banks and their partners under many different kinds of legislation, is the materially present potentiality at and of the points of transaction triggered by part-signs whose traces constitute raw data that may be transformed for use in the security, promotional, gaming, etc. sectors through mining operations. The discovery of new knowledge by data mining operations tends toward an increasingly speedy, cheap, and analytically sophisticated category cross-linking independent data records toward the construction of a 'virtual database' by governments emboldened by post- $9 / 11$ antiterrorist legislation (Gandy 2006). A virtual database results from a creative extrapolation from what is known to what is unknown and most commonly is a profile. The actions of a-signifying part-signs can be employed automatically against models toward the generation of such a profile. 'Guattari has imagined', wrote Deleuze circa 1990, 'a town where anyone can leave their flat, their street, their neighbourhood, using their (dividual) electronic card that opens this or that barrier; but the card may also be rejected on a particular day, or between certain time of the day; it doesn't depend on the barrier but on the computer that is making sure everyone is on a permissible place, and effecting a universal modulation' (1995:181-82). Both Deleuze and Guattari alert us to the diagrammatic modulations that navigate the a-signifying part-signs and work across, between and beyond the barriers as data reservoirs, not merely passively gathering but exploring, filling in the vacuoles, according to constraints of models and analyses. A dividual is an informatic diagram pointing at the virtual but dropping a line to an offline individual who is merely one of its actualizations because nobody totally corresponds to their data double or silhouette; this doesn't help when the police knock on your door in the middle of the night, because a good enough relation suffices.

Triggering is the key action of part-signs. This is Guattari's sense of the passage of molecular signs: machinic superempowerment and diagrammatisation. Guattari extricates himself from the Peircean trap of subsuming diagrams under Icons (within the Logic diagrams are graphic representations - sketches, graphs, drawings, skeletons - in mathematics) and then gains the positive implications of losing aboutness as a criterion, bringing him into constructive coherence with a critique of representation. He splits the image and diagram; the former belongs to symbolic semiologies, and the latter to a-signifying semiotics (the domain of machinism). In shifting into a molecular-machinic modality of explication, Guattari highlights 
a tightly controlled repetition, whose deployment is open-ended, but whose operations are not, as a key aspect of the part-signs.

Part-signs 'support a mode of molecular semiotisation of a nearly unlimited scope' with the proviso that they 'quantify the possible' and elude all signifying representations, to which they remain effectively 'blind' (1979:224). Thus, Guattari continues: 'algorithmic, algebraic and topological logics, recordings, and data processing systems that utilize mathematics, sciences, technical protocols, harmonic and polyphonic musics, neither denote nor represent in images the morphemes of a referent wholly constituted, but rather produce these through their own machinic characteristics'. The concept of constraint should not be confused with a machine's degree of openness. Constraints modulate a diagram's movements, selections, passages and temper its deterritorializations, otherwise part-signs are no longer 'able to cling to all the abstract spaces of machinic potentialities' (Guattari 1979:223). Diagrammatic part-signs are dynamic and productive (capable of multiple articulations) but rigorously constrained - meaning is not essential in this activity but specific codes, algorithms, materials and standards are. To be sure, Guattari notes the 'production of unedited conjunctions' (Guattari 1977b:259) in a-signifying assemblages but this diverges from the uncontrollability of polysemy. Neither uncontrollable slippage and free play nor Peircean-syle multiplication of triads suffices to describe part-signs. Yet what is an unedited conjunction against these rather severe constraints presented by Guattari? 'There isn't anything to 'comprehend' in the equations of theoretical physics', Guattari stated, which is to say that mathematical expression is tightly and technically circumscribed and not beholden to some qualitative content, metaphorical or otherwise. Guattari is not claiming that physicists don't have ideas or have nothing in mind when they are working out problems experimentally and mathematically.

Diagrammatism, in Guattari's hands, blazes a trail beyond the human and individuated subject (of the statement) into the collective machinic dimension, escapees from the prison house of meaning: 'We leave the terrain of signification,' Guattari wrote, 'for that of the plane of machinic consistency', that is, the continuum of interactions on which any machine is reducible to an individual only arbitrarily. There is no 'refolding' or 'returning' or 'reterritorialisation' onto representation or any kind of 'pre-signification' or even overcoding, by either consciousness or iconicity; instead, the part-signs work next to and creatively with the material fluxes. Beyond the double articulation of linguistics, Guattari heralds 'a pluralism of articulations' (Guattari 1977b:259). With a-signifying semiotics one enters the plane of the post-human, 'more and more artificial'. Guattari (1977b:264) didn't shed any 'humanist tears' over this, rejecting anti-modern and anti-machine recapitulations of humanism.

While it is relatively straightforward to appreciate Guattari's splitting of diagrams from icons and substitution of reproductive for productive force, his reconfiguration of Hjelmslevian terms is more complex. For Guattari, what he called an 'abstract machine' like a diagram was akin to the concept of form borrowed from Hjelmslev; unlike Hjelmslev for whom forms are recognized in substance, even though he was ambivalent about which substance was at issue, Guattari used form independently of substance (formed matter) but linked it to semiological and symbolic signification stratified by the two planes of expression and content. And matter, unformed but not amorphous (or uninterrupted), was the site, for Guattari, of material intensities and the haunt of a-signifying part-signs in flux. For Hjelm- 
slev, form was like a net whose shadow (substance) was cast on the surface of an unformed matter. For Guattari, abstract machines were conjoined with material fluxes and partial-signs, but without producing well-formed expression and content substances like 'transcendentalised subjects', or meanings 'embedded' in syntagmatic and paradigmatic chains and clusters, or even affinities between subjects and substances of the statement (Guattari 1977b:267). Rather, the subjectifications at work here are collective - human and post-human. The articulations at issue do not obey, for example, the structuralist fetish for 'Chinese boxes' - hierarchically organized ever widening isomorphic systems all obeying the same rules. Guattari rejects this carefully cultivated sphere for the sake of semiotic intensities that he made to run the gauntlet of signifying propriety on the way towards more open and experimental machinic conjunctions of the formal abstract machines with various fluxes. Worms and viruses as abstract diagrammatic machines conjoin with the digital strand of the machinic phylum and release tendencies of imperfect selfreplication, that is, machinic mutation (Parikka 2007:260ff). It is possible to hack a-signifying machinic part-signs and in so doing reveal the relations of power that condition them and perhaps even expose that the network itself is a system of representation that offers too much consistency and thus produces inertia.

\section{Where Meaning Was Technopolitics Will Be}

Meaning may not be essential, but politics is (the requirement of meaning in politics is of course a complex challenge that cannot be adequately met here). All molecular phenomena display, for Guattari, a politics in lieu of a signified. The sign-particles are no different in this respect, though on the face of it the move to quantity and machinic interactions (automated triggers) belies it. Let's return to our magstripe. On the stripe, which is located in a certain position on the plastic card, there are several tracks. These are not neutral tracks upon which the particles are lined up. Rather, of the three tracks available, the first was developed for use by the airline industry and financial institutions use the second. Each track's format was developed by and for specific interests. The cards meet a variety of internationals standards, and function by means of specific algorithms. Recall the phrase quoted above: a-signifying machines may be used to 'automate' the messages of the signifying semiologies that, in a capitalist system, begin stirring at a young age, especially around the institution of credit. This is one reason why I have paid close attention to bank and credit cards

On the fringes of infocapitalism there are no bank machines that will take your card; networks are finite. The networked radiation of the a-signifying part-signs that automatically trigger anonymous at a distance verification processes find their machinic potentiality temporarily exhausted as the banking systems like Cirrus, Interac, Plus and the rest terminate until further notice. A-signifying semiotics are perfectly adapted to the networked banking systems we use on a regular basis. Their diagrammaticity mobilizes for the next extensions not yet actualized of the cash networks and placements of automated tellers and new magstripe tracks colonized by the next corporate players, and by the coordinated triggers that may just ensure that you and your money can be parted just about everywhere.

Information precedes signification, the potentialities of which are in machinic systems, the site for the study of a-signifying semiotics. Repetitive machinic signaletic stimuli are the stuff of the infocapitalist technoverse. But these are not the signals of an older semiotics. Rather, Guattari's originality as a semiotic theoreti- 
cian lies precisely in his innovative investigation of the characteristics of a-signifying part-signs and how they belong to the very texture of the informatic strand of the machinic phylum. He didn't forgo signifying semiologies and meaning-effects but rather operated a displacement so that the unwarranted hierarchisation of sign types inherited from structuralism could be retheorised; indeed, Guattari gave free rein to the overcodings and complexes in his analytic work. He certainly wasn't an apologist for automation because he insisted on understanding the political dimension of the deployment of part-signs; and after all, non-storage magstripe technologies are not 'smart' enough - do not store the data - to make independent decisions about your credit, but the potential for this completely automated and non-human practice remains, not as a standing-reserve but as a tendency a glimpse of which one catches through the vague mists of virtuality and occasionally sees in the trial and error runs new product actualizations to which such potential seems inassimilable, except in the eyes of an Orwell; less extreme would be the exploratory visions of those like John Willinsky (1999) who imagine metanarratives in the form of virtual public corporations with the capacity to perform automated data mining of knowledge gleaned from all the social sciences. Guattari regained signals towards the end of establishing the semiotics of the leading strand of machinic phylum informatics - more and more held hostage by corporations in what is known as the surveillance postindustrial complex.

The means of conceiving an alternative outcome, an escape from machinic enslavement by IWC, may still be nurtured. The problem is: does this mean that asignifying semiotics simply and only obey a network form and thus resistance dislodged from it must take its form and is, in fact, determined for the network is hegemonic (another master signifier) - for even the state is thought to be an organizational and political network (Castells 2000:338ff) - and the multitude is a distributed one (Hardt and Negri 2004:88), too? Obviously the key to overcoming this straightjacket of technological deterministic formal correspondence would be to look at the alternative ontological universes opened by a-signifying semiotics and the kind of subjectivities attached to them. Technically identical a-signifying declensions may unfold differently in the production of profoundly different universes and subjectivities - security professionals as opposed to hackers of various allegiances. Signaletic matter is not neutral, it is not waiting there passively to be formed, either. Beyond the myth of representation that injects and maintains passivity into semiosis, part-signs retain their plasticity and retain some of their intensivity, that is, they move onward rather than backward (merely receiving sense from their anchors), and for political ends retain a partial signifying sense in their multiple articulations. In this manner they may be nurtured in the non-linear ecologies of networked life by diagrams that 'twist' their tendencies and 'blur' their encounters with formalized strata.

\section{References}

Roland Barthes, Elements of Semiology, trans. A. Lavers and C. Smith, New York: Hill and Wang, 1967.

Bruno Bosteels, 'From Text to Diagram: Towards a Semiotics of Cultural Cartography', in Semiotics 1994, eds. C.W. Spinks and J. Deely, New York: Peter Lang, 1995.

Manuel Castells, End of Millennium, Oxford: Blackwell, 2000.

Umberto Eco, A Theory of Semiotics, Bloomington: Indiana University Press, 1976. 
Manuel DeLanda, War in the Age of Intelligent Machines, New York: Zone, 1991. Gilles Deleuze, 'Postscript on Control Societies', in Negotiations 1972-1990, trans. M. Joughin, New York: Columbia, 1995.

--- Cinema 2: The Time-Image, trans. H. Tomlinson and R. Galeta, Minneapolis: University of Minnesota Press, 1989.

Oscar Gandy, 'Data Mining, Surveillance, and Discrimination in the Post-9/11Environment, in The New Politics of Surveillance and Visibility, eds. K. Haggerty and R. Ericson, Toronto: University of Toronto Press, 2006.

Félix Guattari, The Anti-Oedipus Papers, trans. K. Gotman, New York: Semiotext(e), 2006.

--- 'Machinic Junkies', in Soft Subversions, New York: Semiotext(e), 1995a.

--- Chaosmosis, trans. P. Bains and J. Pefanis, Bloomington: Indiana University Press, 1995b.

--- Cartographies schizoanalytiques, Paris: Galilée, 1989.

--- L'inconscient machinique, Fontenay-sous-Bois: Recherches, 1979.

--- La Révolution Moléculaire, Paris: 10/18, 1977a.

--- La Révolution Moléculaire, Fontenay-sous-Bois, 1977b.

Scott Lash, Critique of Information, London: Sage, 2002.

Brian Massumi, A user's guide to Capitalism and Schizophrenia, Cambridge, MA:The MIT Press/Swerve Edition, 1992.

Jussi Parikka, Digital Contagions, New York: Peter Lang, 2007.

Michael Ruse, 'Signal', in Encyclopedia of Semiotics, ed. Paul Bouissac, New York: Oxford University Press, 1998.

Inna Semetsky, 'Semiotics' in The Deleuze Dictionary, ed. A. Parr, Edinburgh: Edinburgh University Press, 2004.

Janell Watson, 'Guattari's Black Holes and the Post-Media Era', Polygraph 14 (2002).

John Willinsky, Technologies of Knowing, Boston: Beacon Press, 1999. 